\title{
Experiencia en Uruguay de georreferenciación de la documentación gráfica del Archivo Nacional de Planos de Mensura
}

\author{
María Inés García* \\ Andrea Armani* \\ Inés Lejavitzer* \\ Enrique Luque** \\ Lucía Báez ${ }^{* *}$ \\ Diamela Martínez ${ }^{* *}$
}

Recibido el 17 de febrero de 2016; aceptado el 3 de octubre de 2016

\begin{abstract}
This article briefly present some of the results obtained in recent years in the Archivo Nacional de Planos de Mensura (Ministerio de Transporte y Obras Públicas $-M T O P$ ) and in the Georeferencing project of the MTOP-Fundación Ricaldoni agreement. This work addresses, on the one hand, the history and current situation of the archive, and on the other, the tools applied to achieve greater access to the information, such as web publishing and georeferencing. Also, it delves into the experience of applying this tool to the surveyor maps, detailing background, design decisions, procedure and the subsequent online publication.

Key words: graphic archive, surveyor map, georeferencing, geographic information.

\section{Resumo}

No presente artigo descreve-se brevemente alguns dos resultados obtidos nos últimos anos no Archivo Nacional de Planos de Mensura da Direção Nacional de To-

* Archivo Nacional de Planos de Mensura-Dirección Nacional de Topografía- Ministerio de Transporte y Obras Públicas, Uruguay, correos electrónicos: maria.garcia@mtop.gub.uy, andreaarmani23@gmail.com, ineslapoujade@gmail.com

** Fundación Ricaldoni-Facultad de Ingeniería, Universidad de la República, Uruguay, correos electrónicos: enriqueluque@gmail.com, lbaezbaptista@gmail.com,diamemr@gmail.com
\end{abstract}


pografia do Ministério de Transportes e Obras Públicas do Uruguai (MTOP), assim como o Projeto de Georreferenciamento do mesmo arquivo no marco do Convênio MTOP-Fundação Ricaldoni. Se abordam, por um lado, os antecedentes e a situação atual do fundo documental do arquivo, e por outro, as ferramentas aplicadas para lograr um maior acesso a informação do mesmo, através da publicação web e do georreferenciamento. Aprofunda-se a experiência de aplicar esta última ferramenta aos planos de medição, detalhando antecedentes, decisões de desenho, procedimento e posterior publicação on line.

Palavras chave: arquivo gráfico, plano de medição, georreferenciamento, informação geográfica.

\section{Resumen}

En el presente artículo se describen brevemente algunos de los resultados obtenidos en los últimos años en el Archivo Nacional de Planos de Mensura de la Dirección Nacional de Topografía del Ministerio de Transporte y Obras Públicas de Uruguay (MTOP), así como en el Proyecto de Georreferenciación de dicho archivo en el marco del Convenio MTOP-Fundación Ricaldoni. Se abordan, por un lado, los antecedentes y la situación actual del fondo documental del archivo, y por otro, las herramientas aplicadas para lograr un mayor acceso a la información del mismo, como ser la publicación web y la georreferenciación. A su vez, se profundiza en la experiencia de aplicar esta última herramienta a los planos de mensura, detallando antecedentes, decisiones de diseño, procedimiento y posterior publicación en línea.

Palabras clave: archivo gráfico, plano de mensura, georreferenciación, información geográfica.

\section{Introducción}

El Archivo Nacional de Planos de Mensura de la Dirección Nacional de Topografía del Ministerio de Transporte y Obras Públicas (MTOP) de la República Oriental del Uruguay tiene como cometido custodiar, administrar y conservar los planos de mensura de todo el país. Debido a la importancia y volumen de los planos, se ha buscado la forma más eficaz de hacerlos accesibles al público en general. Para ello, el archivo cuenta con un sistema de consulta de información de planos on line ${ }^{1}$ y desde mediados de 2014 se viene realizando la digitalización sistemática de los mismos para su incorporación a una base de datos.

Por otro lado, el Proyecto de Georreferenciación de la documentación gráfica del Archivo Nacional de Planos de Mensura, se enmarca dentro del Convenio de Cooperación entre el MTOP y la Fundación Julio Ricaldoni de la Facultad de Ingeniería de la Universidad de la República, firmado el 26 de diciembre de 2012. El 
trabajo comenzó en junio de 2014, siendo su objetivo realizar la georreferenciación de los planos de mensura de todo el país para su publicación en el visualizador del Nodo Periférico IDE del MTOP, ${ }^{2}$ como forma de mejorar el acceso a esta documentación.

Para llevar a cabo esta experiencia, se analizaron diversas formas de representar la ubicación geográfica de los planos, seleccionando la más adecuada para el proyecto y se realizaron las tareas necesarias para lograr el objetivo propiamente dicho: la clasificación por localidad de los planos escaneados, su georreferenciación automática o manual y la puesta a punto de la capa para su posterior publicación por parte del equipo del geoportal del Nodo Periférico IDE.

\section{Archivo Nacional de Planos de Mensura}

\section{Antecedentes y características}

El Archivo tiene sus orígenes con la creación de la Comisión Topográfica el 3 de diciembre de 1831 y reglamentada el 19 de diciembre del mismo año. La Comisión Topográfica al inicio tenía como algunos de sus cometidos la confección de la Carta Topográfica de la República, precisar límites y demarcaciones de tierras públicas y privadas, regular, examinar y dirigir el ejercicio del agrimensor, informar a los tribunales de justicia sobre las mensuras, así como realizar trabajos para el Gobierno. Esta iniciativa se puede entender como una práctica administrativa y técnica enmarcada en la construcción de un nuevo estado que necesitaba definir su territorio y conocer las tierras que lo componían. Por otro lado, se ve asumida la práctica de agrupar y conservar el resultado de esta tarea técnica plasmada en un plano. (Boulier, J. et. al., 2011).

Actualmente el Archivo Nacional de Planos de Mensura custodia aproximadamente 600,000 planos, y es quien centraliza todos los planos de mensura registrados a lo largo de la historia del país, preservando así una parte indispensable de su memoria cartográfica desde sus inicios. Los planos conservados se encuentran en distintos materiales como cartón, calco, papel cuadriculado, ferroprusiato, tela, hasta llegar a los más actuales en poliéster. Este archivo se encuentra en continuo crecimiento ya que recibe los planos provenientes de la Dirección Nacional de Catastro (DNC) que son registrados mensualmente y dicha documentación no se elimina puesto que es de conservación permanente.

El archivo está conformado por documentos que datan aproximadamente desde el año 1822 hasta el día de hoy. Principalmente custodia documentación gráfica, además de un pequeño porcentaje de documentación textual ya que cuenta con un total de 3,620 expedientes de diligencias de mensuras judiciales, en su mayoría anteriores al año 1900. Asimismo, se conserva una colección denominada "Ciuda- 
des, Pueblos y Villas" (CPV) compuesta de alrededor de 300 planos de fraccionamientos urbanos a partir de principios del siglo XIX.

Los planos de mensura se consideran registrados a partir de 1908 y las oficinas que cumplieron la tarea de registro fueron cambiando con los años hasta que ésta culminó siendo responsabilidad de la DNC. Actualmente según el Decreto $\mathrm{N}^{\mathrm{o}} 318$, Art. $2^{\circ}$, el plano de mensura es definido como:

El documento cotejado y registrado en la Dirección General del Catastro Nacional (o registrado en las dependencias administrativas que con anterioridad tuvieron a su cargo dicho cometido a partir del 2 de enero de 1908) que representa los resultados del acto de deslinde y mensura realizado por profesional habilitado conforme a las Leyes y Disposiciones reglamentarias a la fecha de su registro. El Plano de Mensura documenta la existencia de hechos y/o derechos relacionados con las unidades inmuebles catastrales a la fecha del plano. (Uruguay, DNC, 1995).

\section{Situación actual}

El archivo se enfrenta diariamente a un tipo de usuario cuyo interés es primordialmente legal y el servicio de expedición de copias autenticadas es una de sus tareas fundamentales, puesto que es el único organismo del país habilitado para emitirlas. En los últimos años, con el fin de mejorar su servicio y generar más posibilidades de acceso a la información, se ha trabajado en la mejora de la gestión de la documentación que se conserva a partir de dos aspectos centrales. Primero, la identificación y descripción de los planos mediante el uso de una base de datos a la que se accede con un software especialmente diseñado para ello y por otro lado, la digitalización de los planos de mensura ${ }^{3}$ y su publicación en web. Un amplio porcentaje de las imágenes de los planos se obtuvo a partir de la digitalización de la microfilmación ya existente ${ }^{4}$ y el resto por escaneo directo.

Actualmente se pueden realizar consultas de planos vía web, ver su información asociada y la correspondiente imagen. En cuanto a las posibilidades de recuperación de información, existen criterios de búsqueda recomendados ${ }^{5}$ que permiten la rápida identificación de los planos. Además, se pueden realizar búsquedas más amplias a partir de la selección de otros datos que permitan al usuario utilizar otro tipo de información. De esta manera se amplía el campo de actuación del Archivo en cuanto a sus servicios y se aumenta la cantidad de consultas recibidas.

3 Es importante tener en cuenta que la imagen digital no reemplaza al plano original en soporte físico, sino que trae consigo ventajas en la mejora de la gestión, uso de la información y la conservación documental.

4 La microfilmación se realiza de forma continua debido a la validez legal que posee la imagen en microfilm que se haya obtenido cumpliendo determinadas condiciones.

5 Estos son: el departamento, número y fecha de registro y nombre del agrimensor que firmó el plano. 
La correcta organización junto con la descripción documental y las posibilidades que brinda el uso de bases de datos, son elementos fundamentales para el acceso a la documentación. En este sentido se ha entendido necesaria la normalización de criterios de descripción que permitan reflejar las particularidades de la documentación así como cubrir las necesidades de información de los usuarios. Estos aspectos representan una línea a seguir profundizando con el fin de mejorar el acceso a la documentación por parte de diversos tipos de usuarios, así como posibilitar distintos usos de la misma a otras aplicaciones tales como la georreferenciación.

\section{Georreferenciación de planos de mensura}

A los efectos de este proyecto llamamos georreferenciación a la asociación de un archivo de extensión PDF con su ubicación en el territorio. Resulta importante aclarar que no se busca la visualización del archivo como imagen posicionada sobre él, sino generar para cada plano una entidad geográfica asociada a un link que permita el acceso al archivo correspondiente.

\section{Antecedentes}

La intención de asociar cada plano de mensura del Archivo Nacional de Planos de Mensura con su ubicación geográfica en el territorio uruguayo surge hace varios años. En 2011, a través de un convenio entre el MTOP y la Intendencia de Montevideo, se llevó adelante un proyecto que vincula los planos de mensura registrados desde enero de 1971 a diciembre de 2008 con la cartografía parcelaria de la ciudad de Montevideo a través de un punto georreferenciado. Actualmente se puede acceder en línea a la capa a través del visualizador geográfico de la Intendencia de Montevideo. ${ }^{6}$

A su vez, en el año 2013, ya como parte del convenio MTOP-Fundación Ricaldoni, se comenzó con la georreferenciación de planos de balnearios de la costa del país, abarcando los departamentos de Colonia, San José, Canelones, Maldonado y Rocha. En este caso la georreferenciación se representó a través de un polígono que encierra el área de actuación del plano, ya que, en general abarcan áreas muy extensas.

\section{Fundamentación teórica}

Cada plano contiene información detallada y fehaciente, ya que fue relevado y graficado por un ingeniero agrimensor que estuvo en el lugar y cuya actividad implica la medición, determinación y control de emplazamientos geométricos espaciales. 
230 | María Inés García et al. Experiencia en Uruguay de georreferenciación de la documentación...

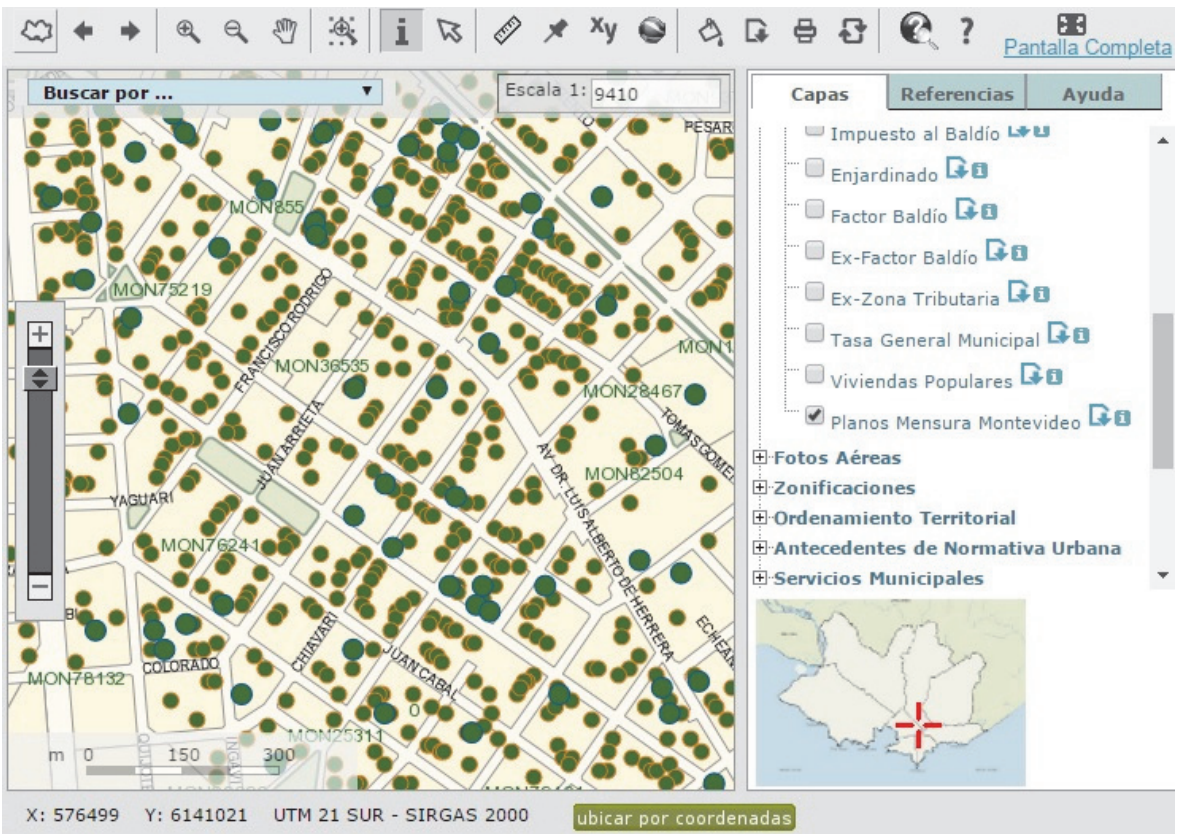

Figura 1. Captura de pantalla de Montevimap con la capa planos de mensura.

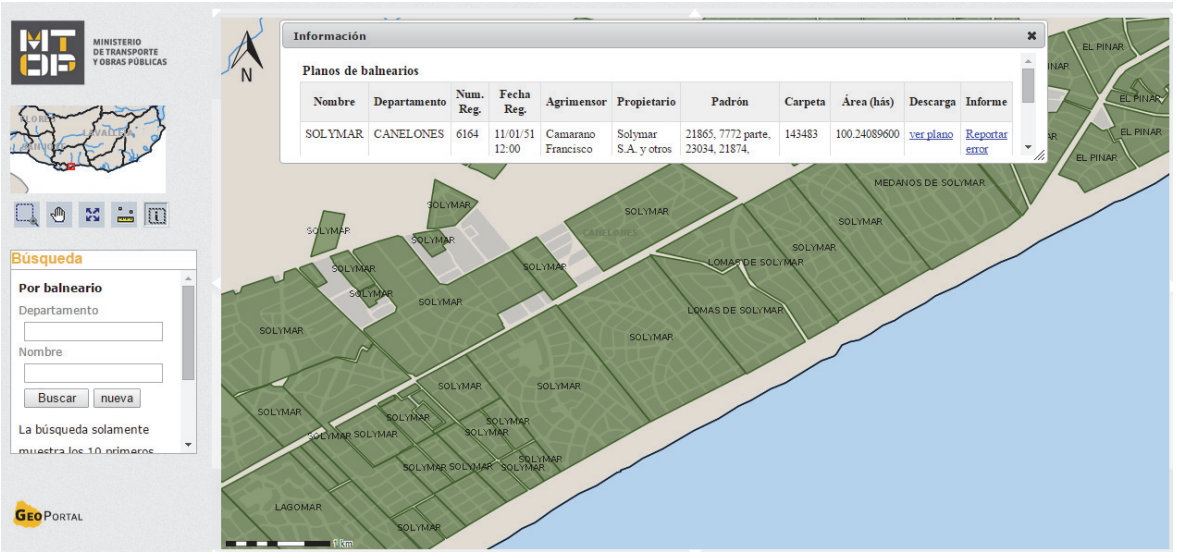

Figura 2. Captura de pantalla de la aplicación de planos de balneario. 
Además de describir aspectos físicos y catastrales de las parcelas sobre los que actúa, cada plano puede significar una fuente más para estudiar la evolución del territorio, ya que en ellos se pueden observar algunos aspectos como la inclusión de detalles de edificaciones (ranchos, iglesias, saladeros, jardines, quintas, espacios públicos, cementerios, entre muchos otros), carreteras, caminos y calles con sus respectivas nomenclaturas, así como elementos paisajísticos como montes y bosques naturales, afluentes de aguas, cañadas, arroyos, lagunas.

Los planos de mensura no sólo son consultados por los ingenieros agrimensores sino también por diversos usuarios, como otros profesionales y público en general. Es de destacar el caso de entes estatales y empresas privadas, cuyo interés generalmente no es un plano en particular sino una zona específica que puede llegar a abarcar grandes extensiones del territorio.

Por dichos motivos, la georreferenciación surge como una herramienta de gran utilidad, ya que reduce los requisitos necesarios para acceder a los planos de interés.

\section{Insumos}

Para realizar este trabajo se cuenta con tres insumos muy importantes: las imágenes de los planos de mensura en formato PDF del Archivo Nacional de Planos de Mensura, su base de datos y el parcelario catastral.

I. Imágenes de los planos de mensura en PDF. Los archivos PDF de la totalidad del país son provistos por el Archivo Nacional de Planos de Mensura. En la etapa actual del proyecto de georreferenciación se están procesando los planos cuya fecha de registro es posterior al año 1970.

II. Base de datos del Archivo Nacional de Planos de Mensura. En esta base de datos generalmente cada registro corresponde a un plano de mensura. Sin embargo, en los casos en que un plano actúe sobre más de una parcela o haya sido firmado por más de un agrimensor, los registros necesarios para almacenar los datos aumentan a la cantidad de parcelas y/o agrimensores involucrados en el plano. Una de las dificultades presentes en el proyecto surge debido a que esto no aplica en planos donde ocurren mutaciones catastrales que mantienen o aumentan el número de fracciones resultantes (reparcelamientos o fraccionamientos). En estos casos el número de padrón asignado a cada nueva parcela no figura en el plano de mensura; por ello, aunque los planos de este tipo generan dos o más lotes en la base de datos se ingresa como un solo registro que responde al número de padrón de la parcela en mayor área.

En esta base se registran una gran cantidad de datos relacionados con el plano, de los cuales para este proyecto se utilizan: departamento; número de padrón; número, fecha y lugar de registro. 
III. Parcelario Catastral. El parcelario catastral, provisto por la Dirección Nacional de Catastro, es un archivo de información geográfica en formato shapefile, formado por polígonos que representan la forma geométrica de las parcelas.

\section{El Decreto N³18/95 define:}

Art. $3^{\circ}$.- Definición de parcela - “... toda unidad inmueble catastral de dominio privado de los particulares fiscal o municipal deslindada, dimensionada e identificada bajo sus aspectos geométrico, económico y jurídico. Se considera como tal toda extensión superficial continua, situada en una misma sección o localidad catastral, que pertenece a persona física o jurídica o a varias en condominio".

Art. $6^{\circ}$.- Identificación parcelaria - Las parcelas catastrales se identifican por un número de padrón, de acuerdo a las normas de nomenclatura que establezca la Dirección General del Catastro Nacional (Uruguay, DNC, 1995).

Es importante aclarar que la República Oriental del Uruguay se divide políticamente en 19 departamentos, donde cada uno de ellos está conformado por una zona rural (suelo categoría rural), y otra zona urbana (suelo categoría urbana) que a su vez está compuesta por diversos centros poblados (localidades catastrales).

La Ley $N^{o} 18.308$ de Ordenamiento Territorial y Desarrollo Sostenible define en el artículo 31 al Suelo Categoría Rural como las áreas del territorio cuyo destino principal es la actividad agraria, pecuaria, forestal o similar, minera o extractiva, como también las áreas protegidas con el fin de mantener el medio natural, la biodiversidad o proteger el paisaje u otros valores patrimoniales, ambientales o espaciales. En el artículo No 32 de la citada ley se define al Suelo Categoría Urbana como las áreas de territorio de los centros poblados, fraccionadas, con las infraestructuras y servicios en forma regular y total. Así como aquellas áreas fraccionadas, parcialmente urbanizadas, en las que los instrumentos de ordenamiento territorial pretenden mantener o consolidar el proceso de urbanización.

Dentro de esta lógica de división del territorio, para identificar una determinada parcela en el país no basta solo con su número de padrón, además hay que tener el dato del departamento y si ésta se encuentra en zona rural o urbana, a su vez en este último caso también es necesario conocer su localidad catastral.

Previo a trabajar con el parcelario catastral, fue indispensable procesarlo para identificar cada polígono con un código único, y eliminar las inconsistencias que presenta, como ser polígonos con igual número de padrón en una misma localidad catastral. Es así que cada polígono se identifica combinando la codificación de catastro para los departamentos (una letra) y las localidades (dos letras), seguido por el número de padrón, y por último, de ser necesario, una letra para diferenciar las parcelas con número de padrón repetido. Por ejemplo, el código autogenerado del número de padrón 544 de la localidad Quebracho, departamento de Paysandú, 
es: ICA544, siendo I y CA los códigos catastrales del departamento y de la localidad respectivamente. A su vez, en caso de que este número de padrón se encontrase duplicado, a cada polígono le correspondería el código ICA544A e ICA544B.

\section{Representación gráfica}

$\mathrm{Al}$ evaluar cómo presentar el proyecto se consideraron varias alternativas y se decidió la más apta de acuerdo a los objetivos del mismo. Éstas fueron:

I. Representar la ubicación de un plano a través de un punto. Representar los planos de mensura con un punto no permite ver la cobertura de los mismos sobre el parcelario, como tampoco el área que abarca cada plano. Además, el punto que representa cada plano debe repetirse sobre cada parcela que tenga relación con él, y en caso de que más de un plano actúe sobre una parcela se debe hacer notar esa superposición de puntos (véase Figura 3).

II. Digitalizar polígonos manualmente utilizando como referencia el parcelario catastral. Digitalizar manualmente los polígonos como en la capa de planos de balnearios mencionada en los antecedentes, resulta útil para planos de grandes dimensiones y que rara vez presentan superposiciones entre sí. Sin embargo, para el caso de este proyecto donde se generan múltiples superposiciones de planos, siendo algunos tan pequeños como una parcela o parte de ésta, la edición de la capa cumpliendo reglas topológicas básicas es particularmente difícil, lo que debido a los tiempos que implicaría hace inviable el uso de esta opción (véase Figura 4).

III. Generar la envolvente de la o las parcelas que abarca cada plano de mensura. Generar la envolvente de las parcelas tiene la principal ventaja de ser independiente del parcelario que se tenga de fondo. Sin embargo, el rectángulo que representa el plano, en general abarca más área de lo que el plano realmente representa, generando muchas superposiciones en lugares donde el plano al que se hace referencia no está relacionado. Ello no permite tener una clara idea de qué parcelas tienen o no, plano de mensura georreferenciado (véase Figura 5).

IV. Asociar a cada PDF una o más geometrías de parcelas existentes en el parcelario catastral actual. Asociar a cada PDF una o más geometrías de parcelas vigentes presentes en la capa "parcelario catastral", permite un cambio casi automático de geometría de la capa en caso de modificación parcial o total de la capa "parcelario catastral" a la que esté relacionada.

En general la geometría de una o varias parcelas puede representar casi con exactitud la geometría de la zona de actuación que abarca el plano de mensura. De todas formas, aún en los casos en que un plano de mensura abarque parcialmente una parcela existente en la base parcelaria que se tenga vigente, es válida la representación del mismo a través de la geometría de la parcela completa, ya 
que lo que se busca con este trabajo es asociar a cada plano un contexto geográfico que está asociado, por lo menos, a una parcela vigente o parte de ésta (véase Figura 6).

Esta alternativa permite ver la cobertura de planos de mensura georreferenciados, así como también los casos donde se superponen los mismos.

V. Utilizar la geometría del parcelario catastral actual, modificándola en los casos que no se corresponda exactamente con lo que abarca el plano.

Esta opción no permite una rápida actualización en caso de cambio de geometría o actualización del parcelario, ya que almacena la geometría en la tabla de planos y éstas en principio pierden relación con las parcelas.

Se debe tener en cuenta que el parcelario catastral es una capa de información que está en continua actualización y que en el mediano o largo plazo, debido a proyectos en curso, va a cambiar geométricamente en su totalidad. Tomar

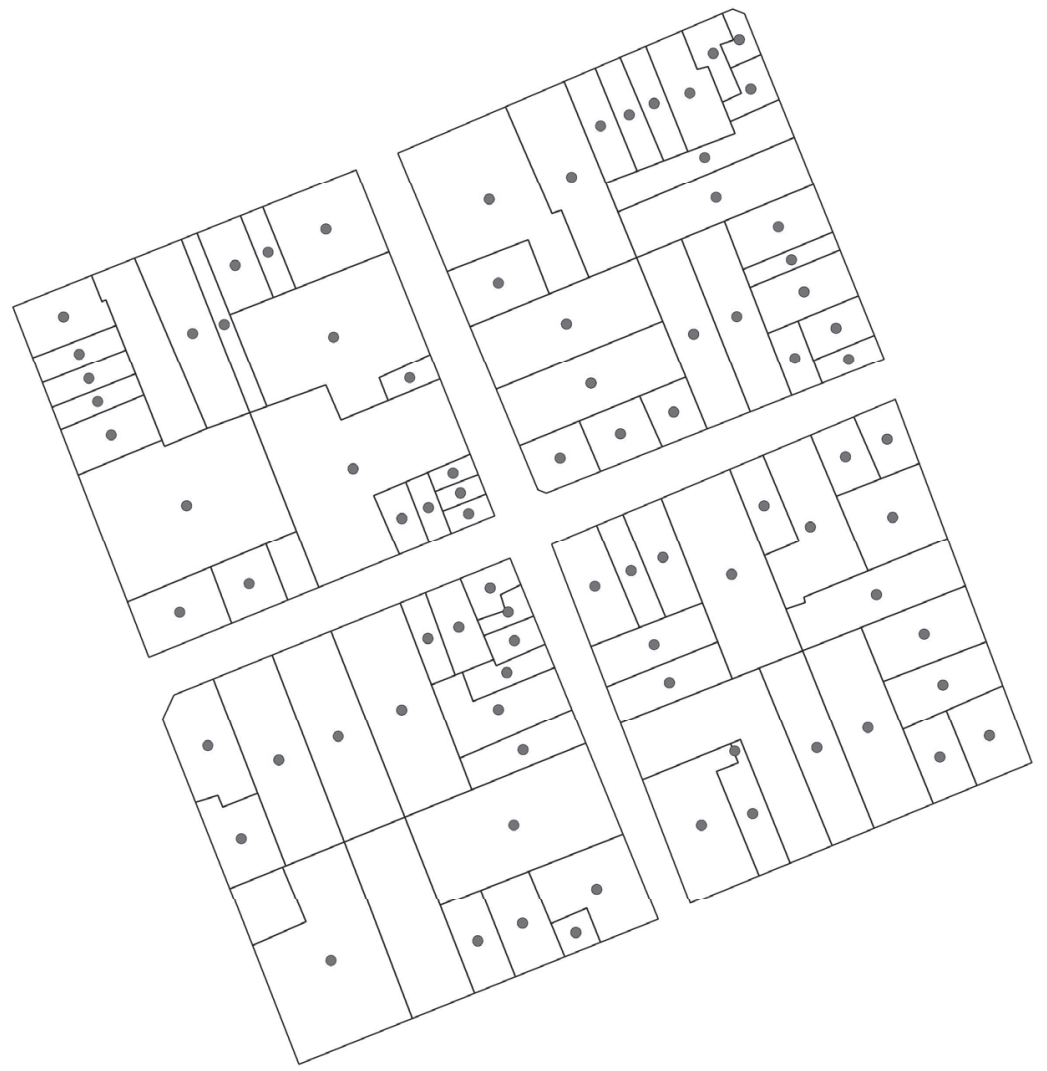

Figura 3. Ejemplo de representación por puntos. 


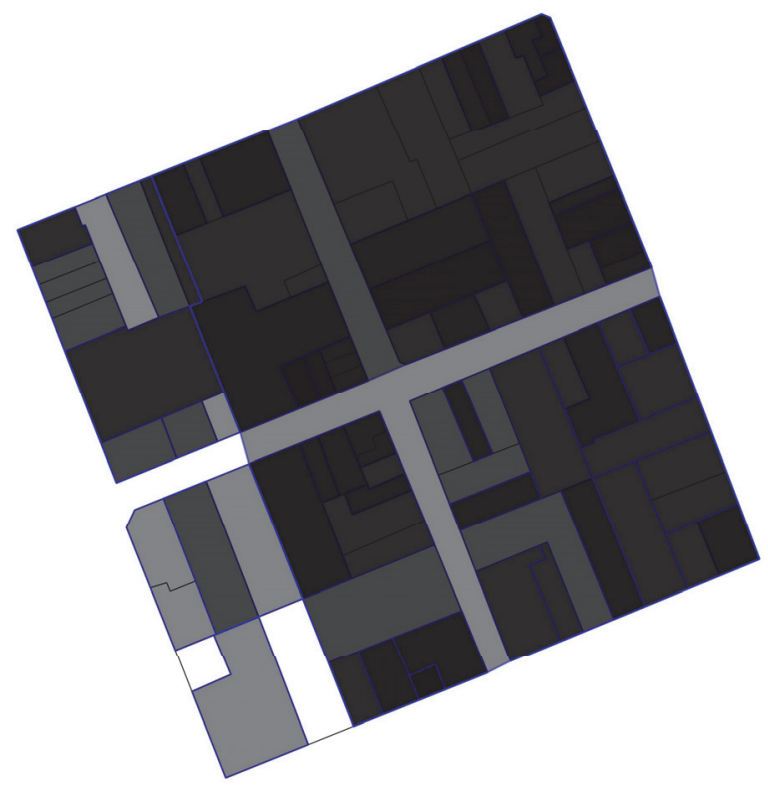

Figura 4. Ejemplo de representación con polígonos digitalizados manualmente.

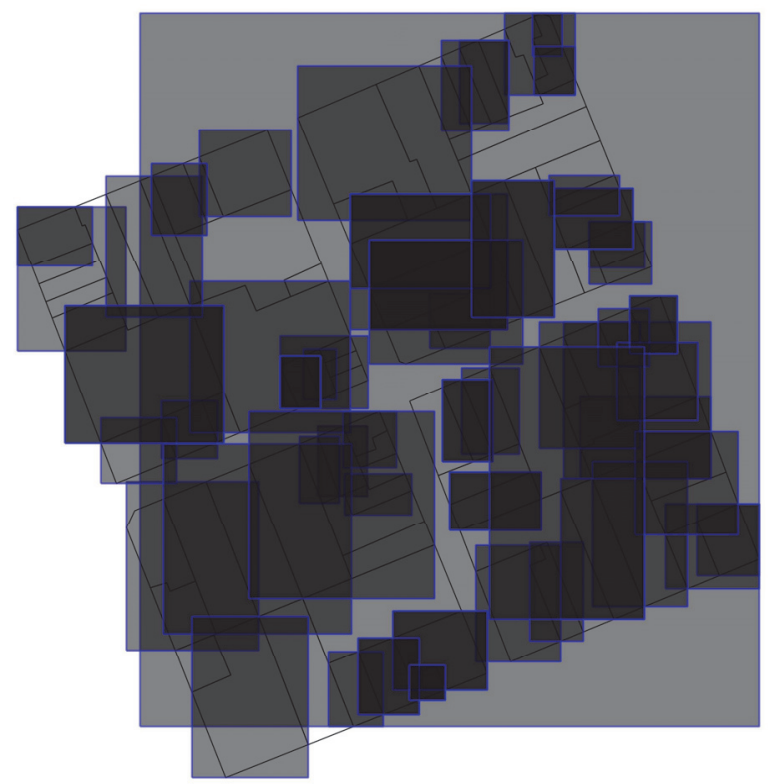

Figura 5. Ejemplo de representación con envolvente de parcelas. 


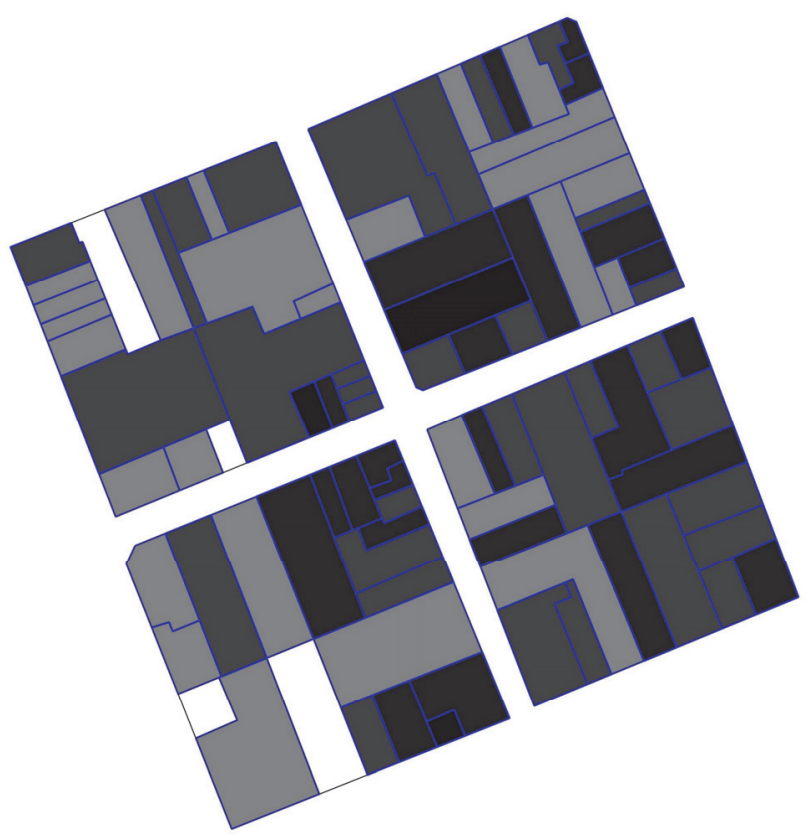

Figura 6. Ejemplo de representación por geometrías de parcelas.

geometrías del parcelario actual, modificarlas y no prever la futura actualización de la forma más automática posible, puede provocar que el producto que hoy se genere no sea visualmente aceptable cuando esto ocurra.

Un ejemplo de esto se puede ver en la Figura 7, donde la imagen de la izquierda representa la superposición de la capa planos de mensura sobre el parcelario actual (en tonos de gris y borde azul) y la imagen de la derecha representa la superposición de la misma capa planos de mensura sobre un parcelario catastral con su geometría modificada en su totalidad.

Dentro de estas opciones se optó por la que asocia a cada PDF una o varias geometrías de parcelas existentes en el parcelario catastral actual sin modificarlas. A continuación se analizan los procesos involucrados para llevarla a cabo.

\section{Metodología}

La metodología de trabajo implica, en primer lugar, la clasificación de los planos por localidad catastral, separando dentro de las mismas aquellos que generen nuevas parcelas seguido por la georreferenciación manual de estas últimas y la georreferenciación automática de las restantes. 

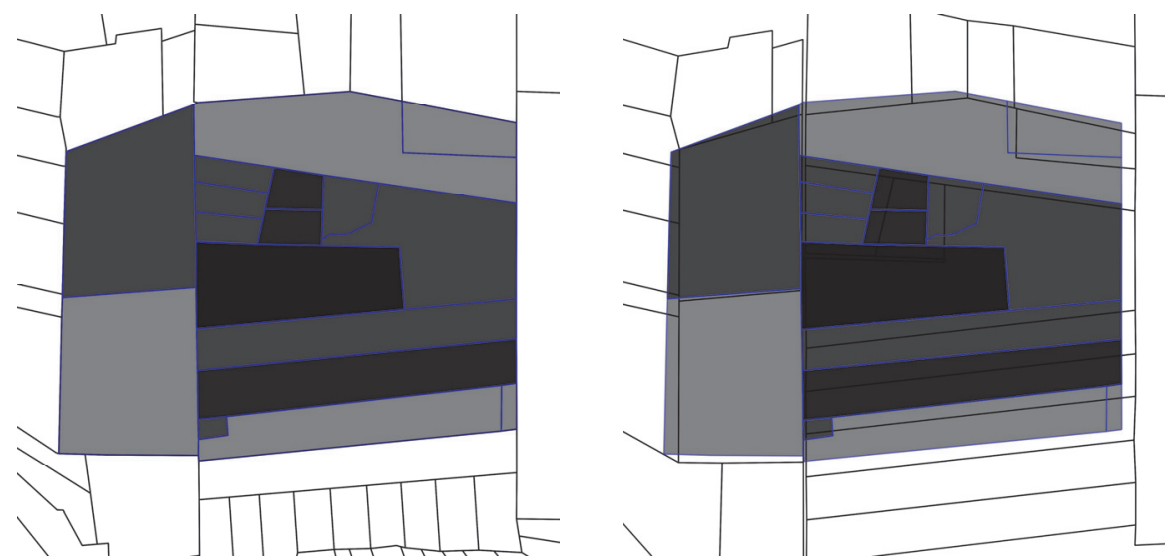

Figura 7. Comparación de geometrías con parcelarios modificados.

Tanto para el proceso de georreferenciación automática como el manual se utilizó el software de sistemas de información geográfica libre QGIS. El sistema de referencia asociado al mismo es el WGS84, proyección UTM zonas 21 Sur Extendido.

\section{Clasificación de archivos PDF}

Para relacionar ambas bases es necesario conocer su ubicación en el territorio, es decir, si pertenece a la zona rural o a una localidad catastral. Este dato se obtiene haciendo una clasificación manual de los mismos, abriendo cada archivo PDF y colocándolo en la carpeta correspondiente a su localidad.

Posteriormente se agrega en la base de datos del archivo de planos el dato de localidad, y utilizando el departamento, lugar y número de registro se crea el campo AUTOGEN correspondiente al nombre de la imagen en PDF.

Durante el mismo procedimiento se separan los planos de cada localidad en dos grupos: los que generan mutaciones catastrales y los que no. Esto se debe a que cada uno sigue un procedimiento distinto a la hora de ser georreferenciado, manual en caso de existir mutaciones y automático en caso contrario.

\section{Georreferenciación automática}

Trabajando con la unión de las bases mencionadas anteriormente se pueden georreferenciar de forma automática un porcentaje importante del total de los planos del Archivo. El resto, que son los planos que generan mutación catastral, se deben geo- 
rreferenciar manualmente, ya que como se explicó anteriormente, no se registró en la base todas las parcelas que surgen de un plano de fraccionamiento.

Cada plano que figura en la base del archivo de planos tiene asociado su número de padrón y, siempre que éste se encuentre vigente en la base de parcelario catastral, tomará la geometría de la parcela a través de un proceso informático llamado unión. Este procedimiento implica separar de la base del archivo gráfico los planos de cada localidad y luego crear una unión de tablas entre el parcelario de la localidad en cuestión y la base de planos para esa localidad, esto se hace utilizando el software QGIS, ya que se tiene la base parcelaria en formato shapefile y la base de planos en formato de tabla. En general, casi la totalidad de los planos que no generan mutación catastral quedan georreferenciados con este procedimiento, el resto se debe agregar al grupo de georreferenciación manual.

\section{Georreferenciación manual}

Este procedimiento se le aplica a los planos que generan mutaciones catastrales y a los que no se georreferenciaron automáticamente con el procedimiento anterior. Al contarse con los archivos PDF agrupados por localidad, se procede a abrirlos uno a uno y buscarlos en el parcelario catastral. Como primera opción, se busca algún número de padrón lindero, en caso de no encontrarlo se utiliza en forma excepcional algún otro archivo shapefile auxiliar como ser los ejes de calles (o de rutas en caso de zona rural), escuelas cercanas o cursos de agua, entre otros.

Para construir el polígono que representa la zona de actuación de cada plano se copia la geometría obtenida del parcelario catastral del o los polígonos que tienen relación con el plano, a un nuevo shapefile auxiliar llamado "planos_padron_geo". Cabe aclarar que no se le asocian a cada parcela sus planos antecedentes, sino que, posteriormente se crea un nuevo polígono independiente del parcelario catastral que surge de disolver en un solo polígono aquellos que tengan el mismo plano asociado. Este polígono puede coincidir con el polígono que representa a una parcela en caso de que el plano sea de una que se encuentre vigente. De esta forma la base catastral continúa modificándose a medida que catastro la actualiza y la capa de planos que surge de este proceso se mantiene independiente de esos cambios.

En caso de no poder identificar qué parcelas pueden tener relación con el plano, pero sí cuál es la zona de actuación aproximada del mismo, se representa dicha ubicación con un punto. En algunos casos los datos que se encuentran en el plano no son suficientes para poder conocer la ubicación del mismo, por lo que existe un porcentaje de aproximadamente el $1 \%$ del total de planos que no quedan georreferenciados. 


\section{Producto}

Lo que se genera al georreferenciar los planos es una tabla llamada "planos_padron_geo", que deriva del shapefile auxiliar que se usó en la georreferenciación, donde en la primer columna se encuentra el código de padrón llamado "COD_PAD", y en otra columna el nombre del archivo PDF georreferenciado "AUTOGEN". Esta tabla se utiliza para relacionar los archivos PDF con el parcelario base utilizado.

Cada plano de la lista con que se está trabajando puede estar ninguna, una o muchas veces en la tabla "planos_padron_geo", y a su vez cada número de padrón del parcelario base puede estar ninguna, una o muchas veces en la tabla "planos_padron_geo" (Figura 8).

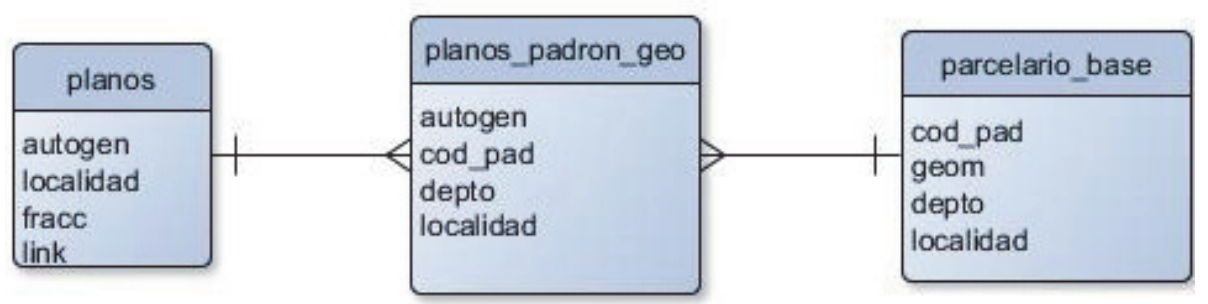

Figura 8. Estructura de tablas, relación muchos a muchos.

Con esta tabla y la de parcelario base se genera una nueva capa que es la que en definitiva se muestra en el geoportal, esta capa toma la geometría de los polígonos que estén asociados al mismo archivo PDF y los disuelve en un solo polígono que representa cada plano, para luego asociar a través de otra tabla el link correspondiente para ver ese plano a través de la página web del Archivo Nacional de Planos de Mensura.

\section{Publicación}

La capa planos de mensura se publica actualmente por tres vías:

I. En el Geoportal del Nodo Periférico del MTOP bajo la categoría Consulta de Planos de Mensura.

La superposición de polígonos, que es habitual en esta capa, se puede apreciar a simple vista ya que la capa tiene configurada una transparencia del $50 \%$ con un color de relleno negro, esto hace que se vea una escala de grises que aumenta en opacidad cuantos más planos se superponen (véase Figura 9).

II. Utilizando Google Earth a través del KMZ que publica el MTOP. 
240 | María Inés García et al. Experiencia en Uruguay de georreferenciación de la documentación...

III. A través del servicio WFS para acceder a la capa de planos desde cualquier software de Información Geográfica (Figura 10).

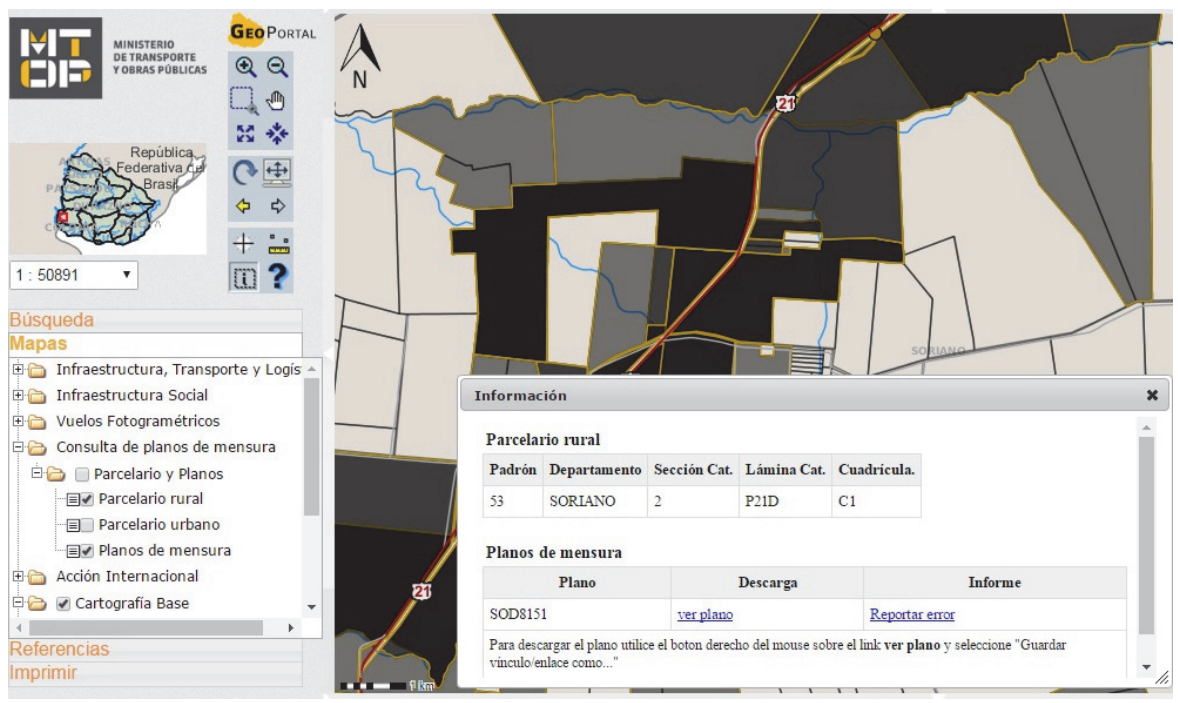

Figura 9. Captura de pantalla del geoportal con la capa de planos de mensura activada.

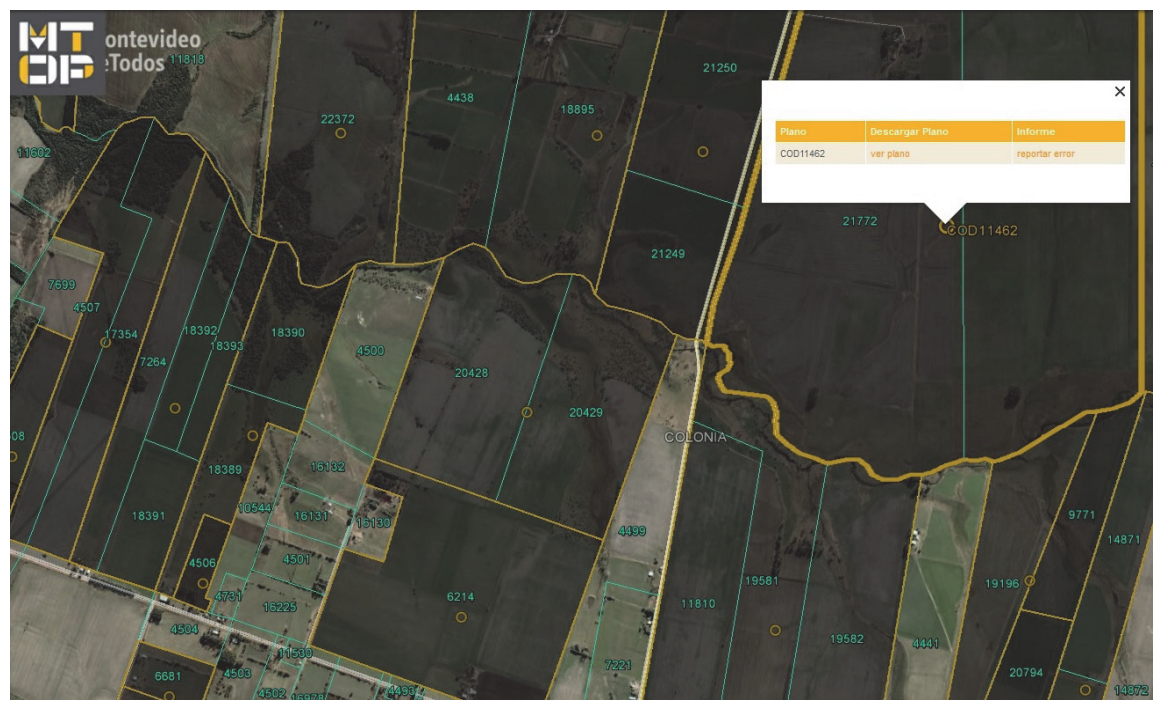

Figura 10. Captura de pantalla de Google Earth con la capa de planos activada. 


\section{Conclusiones}

Actualmente, a dos años del comienzo del proyecto, con un equipo de georreferenciación de tres integrantes, se han procesado 103.760 planos de mensura de los siguientes departamentos: Artigas, Cerro Largo, Colonia, Durazno, Flores, Florida, Lavalleja, Paysandú, Río Negro, Rivera, Salto, Soriano, Tacuarembó y Treinta y Tres. Es decir, aproximadamente un $20 \%$ de la totalidad de planos del Archivo. Un porcentaje importante de estos planos, entre un 35 y $40 \%$, se procesó de forma automática, mientras el resto, menos un $2 \%$ que no pudo ser georreferenciado, se hizo de forma manual.

La metodología del trabajo cumplió con la propuesta inicial para el proyecto y no necesitó de grandes modificaciones. Sin embargo, a través de la experiencia obtenida durante la ejecución del proyecto se incorporaron nuevos criterios que permitieron la mejora del proceso. Por ejemplo, en la clasificación se adoptaron criterios más rigurosos que llevan al aumento del número de planos procesados manualmente, lo cual disminuye considerablemente los errores sin aumentar significativamente la carga de trabajo manual.

Además, en el proceso de georreferenciación se incorporó la representación por puntos, previamente descartada, como forma de representar la ubicación de algunos planos de difícil asociación a polígonos.

A su vez, se tomó una muestra de 2.500 planos para verificar su correcta georreferenciación, obteniéndose un porcentaje de error de la capa de $7,6 \% \pm 1 \%$, resultado que se encuentra dentro de lo esperado para un trabajo de esta naturaleza. El análisis permitió implementar cambios en los procedimientos para evitar los errores de mayor frecuencia. La presencia en la capa de polígonos con menor cantidad de parcelas que las representadas en el plano, justifica casi la mitad del error de la misma y, al producirse principalmente en el proceso automático de georreferenciación, permitió tener mayores posibilidades de influir en su disminución.

Hasta el momento, a pesar de no contar con datos concretos de la cantidad de usuarios que acceden a la consulta web por cualquiera de sus tres vías, se han recibido comentarios positivos respecto de la facilidad que la herramienta reporta en el acceso a la información del Archivo y a las nuevas posibilidades de uso del mismo.

En conclusión, el Archivo Nacional de Planos de Mensura es una fuente de información indispensable para el conocimiento de la evolución de la propiedad en el medio rural, los cambios en la configuración urbanística, los primeros fraccionamientos de ciudades, pueblos y villas, el avance catastral, los cambios de infraestructura en las vías de comunicación y transporte, entre otros. La georreferenciación de los planos facilita al usuario la visualización de esa evolución en la realidad, convirtiéndose en una herramienta muy útil para diversos estudios e investigaciones, así como para conocer y visualizar de forma gráfica la evolución del paisaje, la tenencia de la tierra, los límites administrativos y el territorio del país. 


\section{Bibliografía}

Boulier, J.; Cuénot, J.-F. y Gautreau, P. (2011). “Construcción del Estado e institucionalización administrativa en la provincia de Buenos Aires y Uruguay (18201870): enfoques geohistóricos", en J.C. Garavaglia y P. Gautreau (eds.). Mensurar la tierra, controlar el territorio. América Latina, siglos XVIII-XIX. Prohistoria Ediciones, State Building in Latin America, Rosario, pp. 63-97. Disponible en $<$ https://halshs.archives-ouvertes.fr/halshs-00992284/document $>$

Ministerio de Transporte y Obras Públicas, Dirección Nacional de Topografía, Archivo Gráfico de Planos de Mensura (s/d), Historia medida de un rico patrimonio, MTOP, Montevideo.

Rodríguez, A. (1860). El Digesto nacional: compendio de las leyes, decretos del gobierno y demás resoluciones y actos oficiales de la República oriental del Uruguay, Establecimiento Tipográfico y Litográfico de Luciano Mege, Montevideo.

Uruguay (2008). Ley № 18.308. Ordenamiento Territorial y Desarrollo Sostenible, Montevideo, 18 de junio de 2008, disponible en: <https:/www.impo.com.uy/ bases/leyes/18308-2008/83>, consultado: 19 de agosto de 2016.

Uruguay, DNC, (1995). Decreto $\mathrm{N}^{\mathrm{0}}$ 318, Montevideo, 4 de septiembre de 1995 , disponible en <http://catastro.mef.gub.uy/6565/10/areas/decreto-318_995 Normativa,Decretos,Cotejo-y-Registro.html>, consultado: 19 de agosto de 2016. 